\title{
Effects of biochar amendment on soil aggregates and hydraulic properties
}

\author{
L. Ouyang ${ }^{1}$, F. Wang 2 , J.Tang ${ }^{1}$, L. Yu ${ }^{1}$, and R. Zhang ${ }^{1 *}$ \\ ${ }^{1}$ School of Environmental Science and Engineering, Guangdong Provincial Key Laboratory of Environmental Pollution Control \\ and Remediation Technology, Sun Yat-sen University, Guangzhou 510275, China. ${ }^{2}$ State Key Laboratory of Water Resources and \\ Hydropower Engineering Science, Wuhan University, Wuhan 430072, China. *Corresponding author: zhangrd@mail.sysu.edu.cn
}

\begin{abstract}
The aim of this study was to investigate the effects of biochar amendment on soil aggregate formation and stability, and soil hydraulic properties. Biochar produced from dairy manure was added to two different soils (a silty clay and a sandy loam soil) at a ratio of $2 \%(\mathrm{w} / \mathrm{w}$ in dry weight basis). Incubation experiments were conducted within a 90-d period with the soils (the controls) and the soil/biochar mixtures. Compared with the controls, biochar addition significantly enhanced the formation of macroaggregates and slightly increased saturated hydraulic conductivities of the soils. Attributable to the soil structure change, saturated water contents increased and residual water contents decreased with the biochar amendment. These changes with biochar addition greatly affected the shape of soil water retention functions. For both the soil aggregate formation and the change of soil water retention curves, the sandy loam soil was more sensitive than the silty clay soil to the biochar application on all sampling days. The information from this study should be useful to better understand water processes in the soil with biochar application.
\end{abstract}

Keywords: Biochar, soil aggregate stability, soil water, soil hydraulic properties

\section{Introduction}

Biochar is the pyrolysis product of biomass. As a soil amendment, biochar can greatly influence various soil properties and processes (Lehmann and Joseph, 2009). The presence of biochar in the soil can improve soil chemical (e.g. pH, CEC) (Liang et al., 2006), and physical properties (e.g. soil water retention, hydraulic conductivity) (Major et al., 2010). Aggregate formation and stabilization promotes long term carbon sequestration and soil structural stability and are affected by various factors, including clay content, and types and amount of soil organic matter (SOM) (Six, et al., 2004). Organic materials are the main agents of formation and stabilization of macroaggregates, including persistent cementing agents, such as humic matter, and transient and temporary bonding agents, such as fungal hyphae and microbial extracellular polysaccharides (Six et al., 2004). Acting as a habitat and substrate for soil microorganisms, biochar added in the soil can increase microbial activities (Pietikäinen et al., 2000) In the Terra Preta soils, where biochar is abundant the organic matter, water holding capacity, nutrient-retaining capacity, and bioavailable nutrition elements (e.g., N, P, K, Ca) are higher than those in the adjacent Oxisols (Lehmann and Josehp, 2009) 
With biochar addition, the increase of the availability of soil organic matter, the water holding capacity, and the bioavailable nutrition elements can significantly enhance the microbial activities and thereby the soil aggregate formation and stability (Downie et al., 2009). Glaser et al. (2002) has reported that the formation of complexes of biochar with minerals, as the result of interactions between oxidized carboxylic acid groups at the surface of biochar particles, should be responsible for the improved soil aggregate stability.

Soil hydraulic properties are the key information to predict the processes of water flow and chemical transport in the soil, among which the soil water retention function and saturated hydraulic conductivity are most important (Zhang, 1997). The hydraulic properties, especially the water retention capacity, are closely related to the soil texture and structure (Nimmo, 1997). Various factors influence the soil water retention properties, including organic matter content, the pore size distribution, and the soil bulk density (Hillel 1982). Mohawesh et al. (2005) showed that the saturated water content decreased with the increase in bulk density, and as a result the inflection point on the retention curve shifted to a lower matric potential. Tuli et al. (2005) reported that the air and water permeabilities of undisturbed soil samples were significantly higher than those of disturbed samples, attributed to the changes of soil structure and macropores. Owing to high surface area and porosity of biochar, its addition to soils should influence soil structure and porosity through changing the bulk surface area, pore size distribution, and soil bulk density (Downie et al., 2009; Major et al., 2010). As a result, biochar addition should also affect the soil hydraulic properties. Furthermore, soil aggregates can physically protect SOM from biodegradation and improve the soil structure and the pore size distribution (Tisdall and Oades, 1982), all of which can affect the soil hydraulic properties. Despite several studies, research on the effects of biaochars on soil hydraulic properties is still not clear. Major et al. (2010) found that addition of biochar produced from mango tree increased saturated conductivity in a sandy clay loam soil. On the other hand, Laird et al. (2010) reported that addition of biochar produced from hardwood did not influence saturated conductivity in a fineloamy soil. Novak et al. (2009) observed different effects on soil water retention capacities with addition of biochars produced from different raw materials and temperatures to a loamy sand soil. Since soil texture is an important physical property related to soil aggregation and hydraulic properties (Nimmo, 1997), biochar addition in soils with different textures should affect the soil hydraulic properties differently. Therefore, the objective of this study was to investigate the effects of biochar amendment on the formation and stability of soil aggregates, and on the soil hydraulic properties of two texturally contrasting soils.

\section{Materials and Methods}

\subsection{Production and characterization of biochar}

Biochar was produced from dairy manure using the following procedure. Before charring, the dairy manure was prepared according to the study of Ouyang and Zhang et al. (2013). Briefly, after airdrying, the dairy manure was sieved $(<2 \mathrm{~mm})$, filled into crucibles sealed with lids to prevent from the oxygen entering, and then pyrolyzed in a muffle furnace. In the muffle furnace, temperature increased at a rate of $10{ }^{\circ} \mathrm{C} / \mathrm{min}$ and then was kept at 500 ${ }^{\circ} \mathrm{C}$ for $1 \mathrm{~h}$. After cooling, the biochar was passed through $250-\mu \mathrm{m}$ sieve and stored in a refrigerator (at $4{ }^{\circ} \mathrm{C}$ ) before use. Characteristics of the biochar were examined as follows. Concentrations of elemental $\mathrm{C}, \mathrm{H}$, and $\mathrm{N}$ were determined with the elemental analyzer (Vario EL, Elementar, Germany). Structure and surface characteristics of the biochar were visualized using scanning electron microscopy (SEM) at magnifications of 1000 and 5000 times. Biochar $\mathrm{pH}$ was measured using a $\mathrm{pH}$ probe with a biochar:water ratio of 1:5. Volatile matter was estimated based on the weight loss of biochar after 6 min combustion at 900 ${ }^{\circ} \mathrm{C}$ in a ceramic crucible (Zimmerman et al., 2011). 


\subsection{Soil collection and experimental design}

Two different agricultural soils, a silty clay soil and a sandy loam soil, were collected from the soil surface $(0-20 \mathrm{~cm})$ of a field without tillage in Guangzhou (2303'22.6” N , 11322'55” E, $300 \mathrm{~m} \mathrm{H}$ ), Guangdong Province in South China. After air-drying, soil large macroaggregates were broken down and the soil samples were sieved with a $250-\mu \mathrm{m}$ sieve. The texture of the silty clay soil was composed of $6.6 \%$ sand, $41.8 \%$ silt, and $51.6 \%$ clay, while that of the sandy loam soil was of $60 \%$ sand, $20 \%$ silt, and $20 \%$ clay. The total $\mathrm{C}$ and $\mathrm{N}$ of soils were measured with an elemental analyzer (Vario EL, Elementar, Germany). Soil $\mathrm{pH}$ was measured using a $\mathrm{pH}$ probe at a soil: water ratio of 1:5.

To measure soil aggregation, an incubation experiment was conducted at $25^{\circ} \mathrm{C}$ for $90 \mathrm{~d}$ as described below. The biochar was mixed into the two soils at a ratio of $2 \%$ (w:w in dry weight basis), respectively (Novak et al., 2010), and the soils without biochar addition acted as the control, resulting in four treatments: the sandy loam soil without biochar (SL), and the sandy loam soil with biochar (SLB), the silty clay soil without biochar (SC), the silty clay soil with biochar (SCB). The bulk density of the mixtures of soil and biochar was calculated as follows (Adams, 1973):

$$
\rho_{b}=100 /\left[\left(x / \rho_{1}\right)+(100-x) / \rho_{2}\right]
$$

where $p_{b}$, is the bulk density of the mixtures $\left(\mathrm{g} \mathrm{cm}^{-3}\right)$, $x$ is the percentage by weight of biochar, $p_{1}$, is the bulk density of biochar $\left(\mathrm{g} \mathrm{cm}^{-3}\right), p_{2}$, is the soil bulk density $\left(\mathrm{g} \mathrm{cm}^{-3}\right)$. Based on Equation (1) and bulk densities of $1.40 \mathrm{~g} \mathrm{~cm}^{-3}$ for SL, $1.20 \mathrm{~g} \mathrm{~cm}^{-3}$ for SC, and $0.35 \mathrm{~g} \mathrm{~cm}^{-3}$ for the biochar, the bulk densities of SLB and SCB were calculated as 1.32 and $1.15 \mathrm{~g} \mathrm{~cm}^{-3}$, respectively. Each of the mixtures of soils and biochar or the soils alone was filled into a $500-\mathrm{mL}$ pot based on the bulk densities above. Each treatment was set up in quadruplicate. The filling process was based on the calculated bulk densities above and a moisture content of $80 \%$ of the field moisture capacity (i.e., the water content at $-1 / 3$ bar). During the incubation period, soil moisture contents were kept almost constant by weekly adjustment based on weight losses.

To measure changes of the saturated hydraulic conductivity $\left(K_{s}\right)$ and the water retention curve during the incubation period, samples of each treatment were filled into glass cylinders (each glass cylinder was 3 $\mathrm{cm}$ of height and $4.5 \mathrm{~cm}$ of diameter with 300-mesh copper wire gauze at the bottom) based on the bulk densities above. Then the cylinders for each treatment were put into a 1-L plastic bottle. The bottle was covered with one piece of plastic sheet to prevent moisture loss. A few small holes were pricked on the plastic sheet to keep the atmosphere pressure inside the bottle. The experiment conditions were the same as those of the incubation experiment above. Three replicates were set up for each treatment on every sampling date (Ouyang and Zhang, 2013).

\subsection{Physical Analyses}

Sampling dates were set on days 10, 20, 30, 40, 50, 60, 70,80 , and 90 after the beginning of the experiments. During these days, soil large macroaggregates $(>2000 \mu \mathrm{m})$, macroaggregates $(250-2000 \mu \mathrm{m})$, microaggregates $(53-250 \mu \mathrm{m})$, and silt and clay factions $(<53 \mu \mathrm{m})$ of the incubated soil samples were measured by the sieving method of Tang et al. (2011). Briefly, a series of sieves were used to obtain the aggregate size fractions. Aggregates were separated by manually moving the sieves up and down about 3 $\mathrm{cm}$ in water for 50 times during a $2 \mathrm{~min}$ period. The aggregates remaining on each sieve were collected, oven dried (at $105{ }^{\circ} \mathrm{C}$ for $24 \mathrm{~h}$ ), and weighed to obtain the oven-dry mass. As an important index of the soil aggregate stability the mean weight diameter (MWD) of soil aggregates was calculated as follows (Tang et al., 2011):

$$
D=\sum_{i=1}^{4} A_{s i} d_{i}
$$


where $i$ is the ith size fraction, $i=1,2,3,4$ represent the aggregate size fractions of soil large macroaggregates, macroaggregates, microaggregates, and silt and clay factions, respectively, $d_{i}$ is the mean diameter of each size fraction (i.e., the mean intersieve size), and $A_{s i}$ is the proportion of water-stable aggregates in each size fraction and calculated by:

$$
A_{s i}=\left(A_{i}-S_{i}\right) /\left\{[M /(1+w)]-\sum_{i=1}^{4} S_{i}\right\}
$$

Here $A_{i}$ is the oven-dry mass of water-stable aggregates collected on each sieve, $S_{i}$ is the oven-dry mass of sand collected on each sieve, $M$ is the oven-dry mass of total aggregates sieved, and $\mathrm{w}$ is the gravimetric moisture content.

Samples were taken on days $1,20,60$, and 90 to measure $K_{s}$ values and water retention curves. Soil $K_{s}$ values were measured using the samples and the falling head method (Klute and Dirksen, 1986). Since we mainly focus on the effect of biochar on soil structure and soil water retention function, we only measured soil water retention data at the low suctions $(0$ to $150 \mathrm{~cm})$ using the hanging water column method (Klute, 1986). Briefly, a drainage (desorption) curve of a saturated soil sample was measured using a buchner funnel with a ceramic plate (with air entry value of 1 bar) connected with a burette by plastic tubing. The sample was put (with good contact) on the ceramic plate of buchner funnel and was saturate from the bottom by keeping a positive head on the funnel (i.e., keeping the water level in the burette several centimeters above the top of the sample). After the sample was saturated, a suction of 10 $\mathrm{cm}$ was set up by keeping the water level of the burette $10 \mathrm{~cm}$ lower (the vertical distance) than the center point of the sample height (i.e. the reference level). After reaching the equilibrium (without water flowing out from the sample), the increased amount of water in the burette was recorded. The procedure was repeated with increased suctions of $20,30,110,130$, and 150 $\mathrm{cm}$ sequentially. After finishing the procedure for 150 $\mathrm{cm}$ suction, the sample was oven dried to determine the water content at this suction. The water contents at other suctions were calculated based on the water content at $150 \mathrm{~cm}$ and the amount of water collected at other suctions (by adding up the water amount from highest suction to the lower suctions sequentially). Since the change of soil water content at high suctions is very small, the water content of an air-dried mixture (or the soil) sample should be close to the wilting point (the water content at suction of $15000 \mathrm{~cm}$ ). The measured soil water retention data and the air-dried water content were used to fit the soil water retention model of van Genuchten (1980):

$$
\theta=\theta_{r}+\left(\theta_{s}-\theta_{r}\right) \frac{1}{\left(1+|\alpha h|^{n}\right)^{1-1 / n}}
$$

where $\theta$ is the volumetric water content $\left(\mathrm{cm}^{3} \mathrm{~cm}^{-3}\right)$, $h$ is the soil water potential $(\mathrm{cm}), \theta_{r}$ is the residual water content $\left(\mathrm{cm}^{3} \mathrm{~cm}^{-3}\right), \theta_{s}$ is the saturated water content $\left(\mathrm{cm}^{3} \mathrm{~cm}^{-3}\right), \alpha$ is the reciprocal of the air entry pressure head $\left(\mathrm{cm}^{-1}\right), n$ is the shape factor of the retention curve. The van Genuchten function was fitted with the soil water retention data and the wilting point using a weighted least-squares approach based on Marquardt's maximum neighborhood method (Marquardt, 1963). Parameters of $\theta_{r}, \theta_{s}, \alpha$, and $n$ were obtained from the fitting procedure.

\subsection{Statistical analysis}

All data were analyzed using the Microsoft Excel (2003). Significance of differences among different treatments and sampling dates were tested by the one way ANOVA in the SPSS software package (SPSS Inc., 2003), in which the post-hoc test of least significant difference (LSD) was used. Differences between the values were considered to be statistically significant at $p<0.05$. The coefficient of determination $\left(R^{2}\right)$ of the nonlinear regression was used to determine the best fitting process of the soil water retention model. 
Table 1. Amount of macroaggregates $(250-2000 \mu \mathrm{m})$ and microaggregates $(53-250 \mu \mathrm{m})$ in different treatments.

\begin{tabular}{|c|c|c|c|c|c|c|c|c|c|}
\hline Treatment & Day 10 & Day 20 & Day 30 & Day 40 & Day 50 & Day 60 & Day 70 & Day 80 & Day 90 \\
\hline \multicolumn{10}{|c|}{ Amount of macroaggregates ( $\mathrm{g} \mathrm{kg}^{-1}$ soil) } \\
\hline SL & $64.6 \pm 2.0^{\mathrm{a}} \mathrm{c}^{\mathrm{b}} \mathrm{B}^{\mathrm{c}}$ & $71.2 \pm 3.1 \mathrm{aBC}$ & $85.8 \pm 10 \mathrm{aDE}$ & $79.2 \pm 4.1 \mathrm{abCDE}$ & $73.9 \pm 1.8 \mathrm{aC}$ & $89 \pm 1.0 \mathrm{bE}$ & $77.2 \pm 1.8 \mathrm{bCD}$ & $50.7 \pm 4.0 \mathrm{aA}$ & $65.4 \pm 3.4 \mathrm{bB}$ \\
\hline SLB & $82.8 \pm 4.5 \mathrm{~d} A \mathrm{BB}$ & $108.4 \pm 4.2 \mathrm{bBC}$ & $83.1 \pm 6.5 \mathrm{aAB}$ & $92.4 \pm 5.8 \mathrm{cB}$ & $94.2 \pm 6.5 \mathrm{bB}$ & $154.9 \pm 12 \mathrm{cE}$ & $102.6 \pm 3.3 \mathrm{dBC}$ & $124 \pm 15.2 b C D$ & $69.2 \pm 3.6 \mathrm{bA}$ \\
\hline SC & $30.7 \pm 1.0 \mathrm{bA}$ & $78.1 \pm 4.8 \mathrm{aDE}$ & $71.2 \pm 2.7 \mathrm{aCDE}$ & $68.9 \pm 1.9 \mathrm{aCD}$ & $82.2 \pm 6.8 \mathrm{abE}$ & $53.6 \pm 12 \mathrm{aB}$ & $60.5 \pm 1.8 \mathrm{aBC}$ & $51.2 \pm 3.8 \mathrm{aB}$ & $19.8 \pm 3.2 \mathrm{aA}$ \\
\hline SCB & $20.4 \pm 1.7 \mathrm{aA}$ & $82.3 \pm 7.0 \mathrm{aCD}$ & $78.8 \pm 4.1 \mathrm{aC}$ & $80.3 \pm 1.9 \mathrm{bCD}$ & $86.3 \pm 4.6 \mathrm{abCD}$ & $90.2 \pm 2.1 \mathrm{bD}$ & $87.0 \pm 1.9 \mathrm{cCD}$ & $50.2 \pm 2.2 \mathrm{aB}$ & $57.2 \pm 1.2 \mathrm{bB}$ \\
\hline \multicolumn{10}{|c|}{ Amount of microaggregates $\left(\mathrm{g} \mathrm{kg}^{-1}\right.$ soil) } \\
\hline SL & $685 \pm 17 \mathrm{bAB}$ & $719 \pm 7.7 \mathrm{bB}$ & $680 \pm 22.6 \mathrm{cAB}$ & $690 \pm 25.6 \mathrm{bAB}$ & $661 \pm 11.5 \mathrm{cA}$ & $689 \pm 21 \mathrm{cAB}$ & $722 \pm 12.1 \mathrm{cB}$ & $717 \pm 5 \mathrm{cB}$ & $649 \pm 18.9 \mathrm{bA}$ \\
\hline SLB & $673 \pm 10.1 \mathrm{bBC}$ & $691 \pm 13.2 \mathrm{bBC}$ & $710 \pm 10.6 \mathrm{cC}$ & $711 \pm 21 \mathrm{bC}$ & $680 \pm 19.8 \mathrm{cBC}$ & $605 \pm 15.9 \mathrm{bA}$ & $753 \pm 8.3 \mathrm{cD}$ & $651 \pm 8.8 \mathrm{bAB}$ & $668 \pm 7.6 \mathrm{bB}$ \\
\hline SC & $427 \pm 11 \mathrm{aA}$ & $540 \pm 6.3 \mathrm{aBC}$ & $530 \pm 11.1 \mathrm{bBC}$ & $504 \pm 6.7 \mathrm{aB}$ & $522 \pm 10.9 \mathrm{bBC}$ & $524 \pm 17.1 \mathrm{aBC}$ & $561 \pm 15.8 \mathrm{bC}$ & $505 \pm 2.7 \mathrm{aBC}$ & $389.6 \pm 9.6 \mathrm{aA}$ \\
\hline SCB & $449 \pm 17.7 \mathrm{aAB}$ & $512 \pm 16.5 \mathrm{aCD}$ & $484 \pm 8.4 \mathrm{aBCD}$ & $448 \pm 11.4 \mathrm{aAB}$ & $458 \pm 10.4 \mathrm{aAB}$ & $510 \pm 19.8 \mathrm{aCD}$ & $520 \pm 11.7 \mathrm{aD}$ & $474 \pm 14.7 \mathrm{aBC}$ & $430 \pm 20.1 \mathrm{aA}$ \\
\hline
\end{tabular}

a The values presented in the columns are mean \pm standard deviation $(n=4) . b$ Different small letters indicate differences among the four treatments (SL: sandy loam soil only; SLB: sandy loam soil + biochar; SC: silty clay soil only; SCB: silty clay soil + biochar) for a single day $(p<0.05)$. c Different capital letters indicate differences among the nine sampling days (day 10, 20, 30, $40,50,60,70,80$, and 90$)$ for a single treatment $(p<0.05)$.

\section{Results and Discussion}

\subsection{Soil aggregates}

The amount of macroaggregates was highest in the SLB in most of the incubation dates (Table 1). The biochar amendment significantly promoted the formation and stabilization of macroaggregates in the sandy loam soil almost within the whole incubation period. However, such biochar promotion did not occur in the silty clay soil, except on a few sampling days. The temporal changes of macroaggregates were similar in all the treatments. Macroaggregates increased at the earlier incubation stage, reached a peak in the middle, and then decreased at the later stage. Specifically, the amount of macroaggregates in SLB increased to the maximum (154.9 $\mathrm{g} \mathrm{kg}^{-1}$ soil) after $60 \mathrm{~d}$ of incubation. In terms of the microaggregates, the treatments in the two soils with and without biochar did not show significant differences in most of the sampling dates. The temporal changes of microaggregates were also not significantly different in all the treatments.
As shown in Figure 1, the MWD values of the sandy loam soil were significantly $(p<0.05)$ enhanced by the biochar addition in most of the sampling days. For the silty clay soil, the MWD differences between the SC and SCB treatments were significant $(p<0.05)$ only at the later incubation stage. Throughout the incubation period, the MWD values were remarkably higher in the sandy loam soil than in the silty clay soil. In the SLB treatment, the temporal distribution of MWD values reached a peak on day $60(0.28 \mathrm{~mm})$.

The biochar amendment enhanced the formation and stabilization of the soil macroaggregates, especially in the sandy loam soil. Aggregate formation and stabilization are affected by the type and amount of organic materials, which include the microorganisms and microbial synthesis (Six et al., 2004), and the quality and amount of residue (Bossuyt et al., 2001). Different materials (e.g., minerals, organic matter) with various molecular sizes and chemical characteristics attached to biochar surfaces might reduce the biochar's surface area at the molecular scale and thus serve as the 
binding agents for the formation and stability of soil aggregates (Liang et al., 2006). As shown by the scanning electron micrographs (Figure 2), the biochar was highly heterogeneous and has relatively high internalsurface area (the left figure), and with high macro-porosity (the right figure). Therefore, the biochar should be able to adsorb soluble inorganic nutrients, and serve as an appropriate habitat for microbial growth and reproduction (Pietikäinen et al., 2000). This condition should produce more transient and temporary bonding agents to promote the soil aggregate formation. Further, the relatively higher $\mathrm{C} / \mathrm{N}$ of biochar (Table 2) used in this study probably created a favorable condition for the growth of fungi (Bossuyt et al., 2001), which played a more important role in the aggregate formation than the bacteria (De Gryze et al., 2005). The MWD values were higher in the sandy loam soil than in the silty clay soil in our study, while in the literature, a higher clay content resulted in more and larger aggregates (Kristiansen et al., 2006; Wick et al., 2009). The difference might be attributable to the very low sand content $(6.6 \%)$ in the silty clay soil, considerably lower than the sand contents ( $37 \%$ to $53 \%$ and $34 \%$ to $79 \%$, respectively) in the studies of Kristiansen et al. (2006) and Wick et al. (2009). The very low sand content in the silty clay soil might create an environment without sufficient aeration for microbial growth. Because of biochar's recalcitrance against microbial degradation and the paucity of easily available $\mathrm{C}$, the promotion of soil aggregation was more likely to happen in the relatively latter stage, that is, MWD reached the peak value and the amount of macroaggregates in SLB increased to the maximum on day 60. Macro-aggregation declined in the later incubation stage probably attributable to the decrease of available resource of biochar. Organic matter is of major importance for the stabilization of aggregates (Six et al., 2004). Macroaggregates generally have a relatively short lifetime because organic matter was degraded with time (Tisdall and Oades, 1982).

\subsection{Soil hydraulic properties}

Table 3 lists the $K_{s}$ values for the different treatments on the sampling days. The $K_{s}$ values of each soil with and without biochar were not significantly different $(p>$ $0.05)$. The temporal variation of the $K_{s}$ values in each treatment was also not significant $(p>0.05)$. Similarly, Laird et al. (2010) showed that biochar amendments did not significant affects the saturated hydraulic conductivity of a typical Midwestern agricultural soil. However, Major et al. (2010) reported that the biochar addition increased saturated hydraulic conductivity from 2.7 to $13.4 \mathrm{~cm} \mathrm{~h}^{-1}$. The different results might be partly attributable to the different characteristics of biochars used. For instance, the $\mathrm{C} / \mathrm{N}$ ratios of biochar in our study (Table 2) and Laird et al. (2010) were much lower than that in Major et al. (2010). The higher ratio of $\mathrm{C} / \mathrm{N}$ is favorable for fungi (Bossuyt et al., 2001), which can excrete hyphae and breakdown complex biopolymers when the resource in environment was limited, and play a more important role in the soil aggregation (De Gryze et al. 2005). The increased amount of hyphae and the improved soil structure can be beneficial for the saturated hydraulic conductivity consequently. In addition, the amount of biochar used may be another factor for the effect on $K_{s}$. The biochar application significantly increased the amount of macroaggregates and decreased soil bulk density, which may result in significantly higher $K_{s}$ values. Nevertheless, the hydraulic conductivity is affected more profoundly by the pore size distribution along flow paths (Tuli et al., 2005). Further research is needed to study the effects of different biochars on the soil hydraulic conductivity and the associated flow dynamics.

Figure 3 shows some typical examples of the effects of biochar amendment on the water retention curves of the soils. For the two soils, the biochar application increased the water content within the low suction range. The water content values vs. the different suctions were in the order of $\mathrm{SCB}>\mathrm{SC}>\mathrm{SLB}>\mathrm{SL}$ during the incubation period. With the biochar application, the water contents over different suctions of the sandy loam soil changed more than those of the silty clay soil on all sampling days. Table 4 summarizes the measured and fitted residual and saturated water contents, the available water content (AWC) (i.e., the difference between the saturated water content and residual water content), 

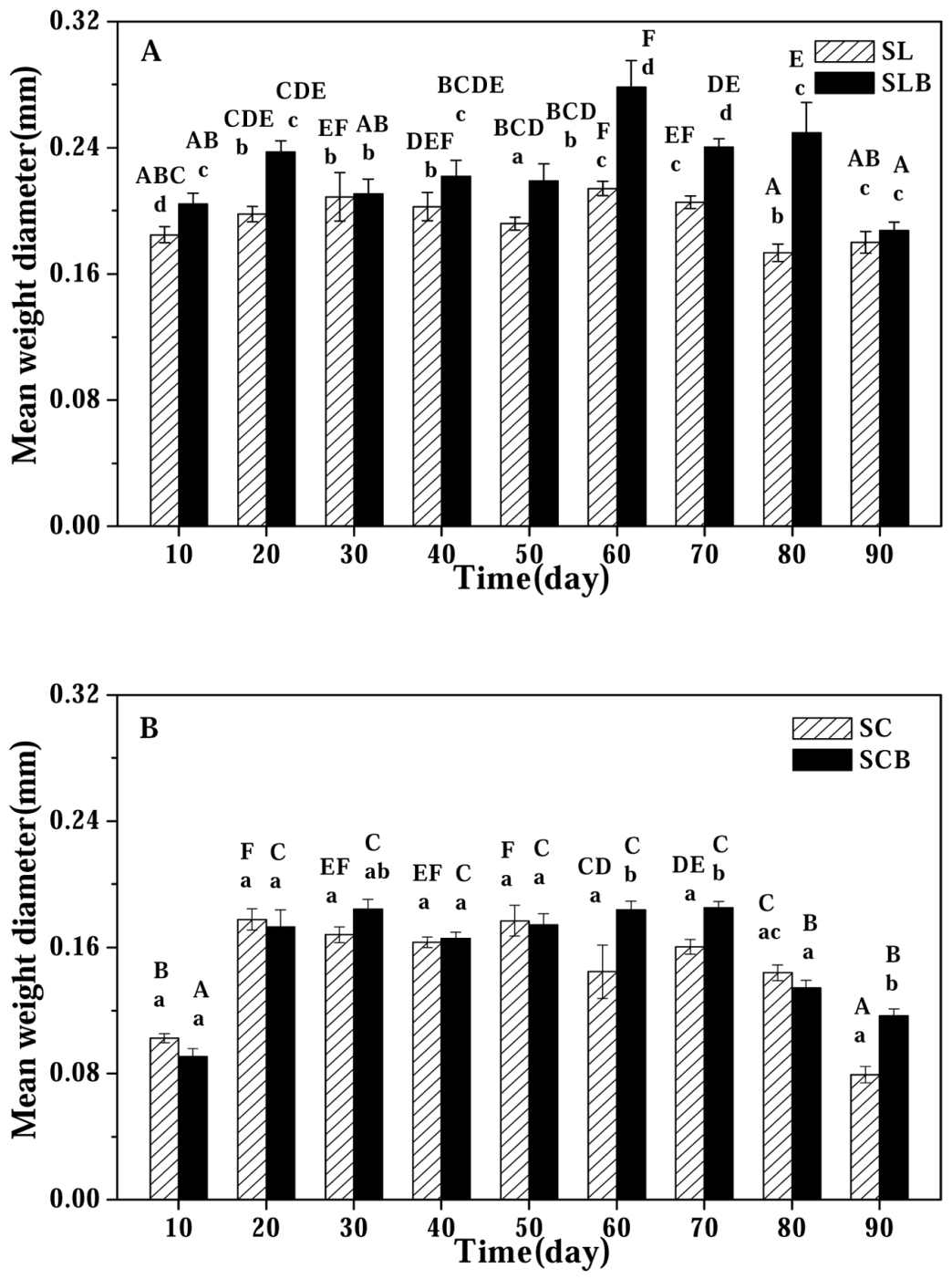

Figure 1. Effects of biochar applications on soil mean weight diameter values of (A) a sandy loam soil and (B) a silty clay soil within different incubation periods. Vertical bars represent the standard error of the mean values $(\mathrm{n}=4)$. Different lowercase letters indicate significant differences between the four treatments (SL: sandy loam soil, SLB: sandy loam soil + biochar, SC: silty clay soil, SCB: silty clay soil + biochar) for a single day $(p<0.05)$. Different capital letters indicate significant differences between the nine sampling days (day 10, 20, 30, 40, 50, 60, $70,80$, and 90$)$ for a single treatment $(p<0.05)$. 

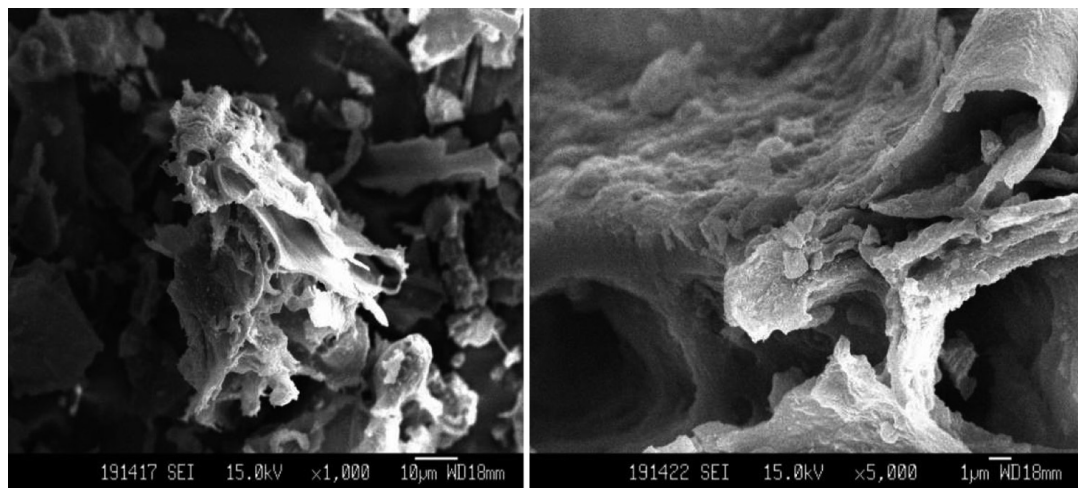

Figure 2. Scanning electron micrographs of biochar.

Table 2. Selected physicochemical characteristics of biochar and soils.

\begin{tabular}{cccc}
\hline Treatment & Biochar & Sandy loam soil & Silty clay soil \\
\hline $\mathrm{pH}(1: 5 \mathrm{w} / \mathrm{v})$ & 10.18 & 6.81 & 6.65 \\
Volatile matter (\%) & 66.30 & -- & -- \\
$\mathrm{C}(\%)$ & 73.87 & 0.735 & 1.169 \\
$\mathrm{H}(\%)$ & 2.423 & 0.595 & 0.975 \\
$\mathrm{~N}(\%)$ & 1.382 & 0.060 & 0.104 \\
$\mathrm{C} / \mathrm{N}$ ratio & 53.45 & 12.25 & 11.24 \\
\hline
\end{tabular}

(--) data was not determined.

and the fitted parameters ( $\alpha$ and $n$ ) of the soil water retention model (van Genuchten, 1980). For both soils, the biochar application increased the saturated water contents but decreased the residual water contents on the sampling days. For the four sampling days, the biochar applications increased the saturated water contents in average by $2.2 \%$ and $7.4 \%$ for the silty clay and sandy loam soils, respectively, whereas decreased the residual water contents by $15 \%$ and $19 \%$ for the silty clay and sandy loam soils, respectively. Therefore, the biochar applications increased the AWC by $5.2 \%$ for the silty clay soil and $10.6 \%$ for sandy loam soil. With the excellent fitting processes (based on the coefficients of determination $R^{2}>0.99$ ), the fitted $\theta_{r}, \theta_{s}, \alpha$, and $n$ values should be reliable. For the soils and the sampling days, the $\alpha$ and $n$ values were similar for the treatments with and without biochar. For the SL and SLB treatments, the $n$ values showed an increased trend with the incubation period.

The soil water retention curve clearly characterizes water content distribution with soil suctions in unsaturated soils. Within the lower suctions, the soil water retention function is mainly dependent on the soil structure, such as larger pore sizes and soil aggregates (Hillel, 1982). In our study, the physical 
properties of biochar enhanced soil aggregate formation and decreased the soil initial bulk density, leading to the change in the soil water retention curve. The direct effect of biochar application on the soil water retention function was related to the high porosity of biochar (Pietikäinen et al., 2000). The increased $n$ values with time for the SL and SLB treatments might also be related to more profound effect of biochar on the sandy loam soil. The biochar applications increased the saturated water contents and decreased the residual water contents through improving soil structure (increasing the amount of macroaggregates and decreasing the amount of microaggregates). As shown in Figure 3, the water retention curves of the same soil with and without biochar crossed at suction about $500 \mathrm{~cm}$, which clearly indicated the increase of larger soil pore sizes and thus the decrease of smaller soil pore sizes with the biochar application. Therefore, designed biochar application should increase available water content to enhance plant and microbial activities in soils.

Table 3. Saturated hydraulic conductivity $\left(\mathrm{cm}^{-1} \mathrm{~d}\right)$ in different treatments.

\begin{tabular}{ccccc}
\hline Treatment & Day 1 & Day 20 & Day 60 & Day 90 \\
\hline SL & $57.67 \pm 6.60^{\mathrm{a}} \mathrm{aA}^{\mathrm{b}}$ & $61.01 \pm 7.79$ & $62.10 \pm 6.70$ & $64.30 \pm 4.50$ \\
SLB & $62.10 \pm 6.90$ & $75.83 \pm 7.03$ & $76.58 \pm 8.69$ & $67.72 \pm 5.69$ \\
SC & $46.84 \pm 4.24$ & $58.49 \pm 3.09$ & $62.06 \pm 4.47$ & $53.24 \pm 2.17$ \\
SCB & $53.30 \pm 6.50$ & $66.67 \pm 9.07$ & $69.94 \pm 1.15$ & $57.60 \pm 2.20$ \\
\hline
\end{tabular}

${ }^{a}$ The values presented in the columns are mean \pm standard deviation $(n=3)$. ${ }^{\mathrm{b}}$ There is no significant difference of saturated hydraulic conductivity among sampling dates and the treatments $(p>0.05)$.

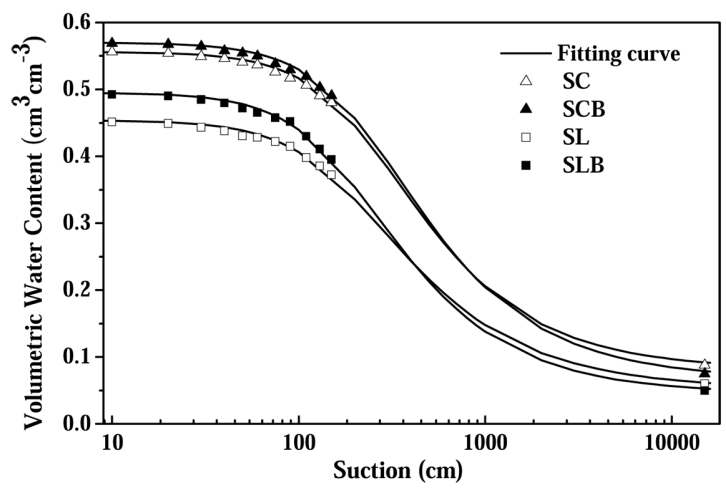

Figure 3. Effects of biochar applications on soil water retention curves of the four treatments (SL: sandy loam soil, SLB: sandy loam soil + biochar, SC: silty clay soil, SCB: silty clay soil + biochar) on day 20 . 
Table 4. Fitted and measured values of the residual water content $\left(\theta_{r}\right)$ and the saturated water content $\left(\theta_{s}\right)$, and the fitted values of parameters ( $\alpha$ and $n$ ) of the soil water retention model (van Genuchten, 1980).

\begin{tabular}{|c|c|c|c|c|c|c|}
\hline Treatment & $\theta_{r}\left(\mathrm{~cm}^{3} \mathrm{~cm}^{-3}\right)$ & $\theta_{s}\left(\mathrm{~cm}^{3} \mathrm{~cm}^{-3}\right)$ & AWC $\left(\mathrm{cm}^{3} \mathrm{~cm}^{-3}\right)$ & $\alpha^{a}\left(\mathrm{~cm}^{-1}\right)$ & $n$ & $R^{2}$ \\
\hline & & & Day 1 & & & \\
\hline $\mathrm{SL}^{\mathrm{b}}$ & $0.057^{c}(0.052)^{d}$ & $0.454(0.454)$ & $0.397(0.402)$ & 0.0058 & 1.778 & 0.9962 \\
\hline SLB & $0.048(0.041)$ & $0.485(0,485)$ & $0.437(0.444)$ & 0.0054 & 1.763 & 0.9962 \\
\hline $\mathrm{SC}$ & $0.083(0.081)$ & $0.550(0.551)$ & $0.467(0.470)$ & 0.0044 & 1.843 & 0.9969 \\
\hline $\mathrm{SCB}$ & $0.073(0.070)$ & $0.565(0.564)$ & $\begin{array}{c}0.492(0.494) \\
\text { Day 20 }\end{array}$ & 0.0043 & 1.926 & 0.9989 \\
\hline SL & $0.053(0.052)$ & $0.454(0.453)$ & $0.401(0.401)$ & 0.0054 & 1.836 & 0.9985 \\
\hline SLB & $0.045(0.043)$ & $0.495(0.493)$ & $0.450(0.450)$ & 0.0055 & 1.914 & 0.9993 \\
\hline $\mathrm{SC}$ & $0.082(0.081)$ & $0.556(0.558)$ & $0.474(0.477)$ & 0.0043 & 1.895 & 0.9984 \\
\hline SCB & $0.068(0.066)$ & $0.570(0.571)$ & $\begin{array}{c}0.502(0.505) \\
\text { Day } 60\end{array}$ & 0.0042 & 1.881 & 0.9974 \\
\hline SL & $0.056(0.051)$ & $0.467(0.466)$ & $0.411(0.415)$ & 0.0061 & 1.868 & 0.9986 \\
\hline SLB & $0.043(0.040)$ & $0.490(0.494)$ & $0.447(0.454)$ & 0.0056 & 1.975 & 0.9991 \\
\hline $\mathrm{SC}$ & $0.077(0.080)$ & $0.546(0.545)$ & $0.469(0.465)$ & 0.0047 & 1.821 & 0.9968 \\
\hline SCB & $0.071(0.069)$ & $0.553(0.554)$ & $\begin{array}{c}0.482(0.485) \\
\text { Day } 90\end{array}$ & 0.0047 & 1.789 & 0.9950 \\
\hline SL & $0.052(0.052)$ & $0.446(0.451)$ & $0.394(0.399)$ & 0.0051 & 2.128 & 0.9987 \\
\hline SLB & $0.043(0.043)$ & $0.485(0.485)$ & $0.442(0.442)$ & 0.0052 & 2.214 & 0.9938 \\
\hline $\mathrm{SC}$ & $0.084(0.085)$ & $0.541(0.542)$ & $0.457(0.457)$ & 0.0045 & 1.820 & 0.9959 \\
\hline $\mathrm{SCB}$ & $0.072(0.075)$ & $0.552(0.552)$ & $0.480(0.477)$ & 0.0045 & 1.832 & 0.9966 \\
\hline
\end{tabular}

${ }^{\mathrm{a}} \alpha$ and $n$ are the shape factors of the van Genuchten model (1980), and AWC is the available water content. ${ }^{\mathrm{b}} \mathrm{SL}$ : sandy loam soil only; SLB: sandy loam soil + biochar; SC: silty clay soil only; SCB: silty clay soil + biochar. ${ }^{\mathrm{c}}$ The fitted values of the residual water content and the saturated water content. ${ }^{\mathrm{d}}$ The measured values of the residual water content and the saturated water content.

\section{Conclusions}

Biochar amendment promoted macroaggregate formation in both soils, and the effect of biochar on macroaggregate formation was more profound in the sandy loam soil than in the silty clay soil. The biochar application only slightly increased saturated hydraulic conductivities of the soils. Biochar addition changed the shape of the soil water retention function through significantly changing the parameters of the function. Biochar amendment increased the saturated water contents and decreased the residual water contents attributable to soil structure changes. The results should provide valuable information to study water flow processes in unsaturated soils with biochar amendment.

\section{Acknowledgements}

This study was partly supported by grants from the Chinese National Natural Science Foundation (Nos. 51039007 and 51179212) and Doctoral Fund of Ministry of Education of China (No. 20120171110040).

\section{References}

Adams, W.A. 1973. The effect of organic matter on the bulk and true densities of some uncultivated podsoilc soils. J. Soil Sci. 24, 11-17.

Bossuyt, H., Denef, K., Six, J., Frey, S.D., Merckx, R., Paustian, K. 2001. Influence of microbial populations and residue quality on aggregate stability. Appl. Soil Ecol. 16, 195-208. 
De Gryze, S., Six, J., Brits, C., Merckx, R. 2005. A quantification of short-term macroaggregate dynamics: influences of wheat residue input and texture. Soil Bio. Biochem. 37, 55-66.

Downie, A., Crosky, A., Munroe, P. 2009. Physical properties of biochar. In: Lehmann, J., Joseph, S. (eds), Biochar for Environmental Management: Science and Technology, Earthscan, London. pp: 13-29.

Glaser, B., Lehmann, J., Zech, W. 2002. Ameliorating physical and chemical properties of highly weathered soils in the tropics with charcoal - a review. Biol. Fert. Soils. 35, 219-230

Hillel, D. 1982. Introduction to Soil Physics. Academic Press, New York.

Klute, A. 1986. Water Retention: Laboratory Methods. In: Klute, A. (ed), Methods of Soil Analysis. Part 1. Physical and mineralogical methods, American Society of Agronomy, Madison, WI, pp 635-685.

Klute, A., Dirksen, C. 1986. Hydraulic Conductivity and Diffusivity: Laboratory Methods. In: Klute, A. (ed), Methods of Soil Analysis. Part 1. Physical and mineralogical methods, American Society of Agronomy, Madison, WI, pp 687-703.

Kristiansen, S.M., Schjonning, P., Thomsen, I.K., Olesen, J.E., Kristensen, K., Christensen, B.T. 2006. Similarity of differently sized macroaggregates in arable soils of different texture. Geoderma 137, 147-154.

Laird, D.A., Fleming, P., Davis, D.D., Horton, R., Wang, B., Karlen, D.L. 2010. Impact of biochar amendments on the quality of a typical Midwestern agricultural soil. Geoderma. 158, 443-449.

Lehmann, J., Joseph, S. 2009. Biochar for environmental management: an introduction.
In: Lehmann, J., Joseph, S. (eds.), Biochar for Environmental Management: Science and Technology, Earthscan, London, pp 1-12.

Liang, B., Lehmann, J., Solomon, D., Kinyangi, J., Grossman, J., O’Neill, B., Skjemstad, J.O., Thies, J., Luiza, F.J., Petersen, J., Neves, E.G. 2006. Black carbon increases cation exchange capacity in soils. Soil Sci. Soc. Am. J. 70, 1719-1730.

Major, J., Lehmann, J., Rondon, M., Goodale, C. 2010. Fate of soil-applied black carbon: downward migration, leaching and soil respiration. Global Change Biol. 16, 1366-1379.

Marquardt, D.W. 1963. An algorithm for leastsquares estimation of nonlinear parameters. J. Soc. Ind. Appl. Math. 11, 431-441.

Mohawesh, O., Fukumura, K., Ishida, T., Yoshino, K. 2005. Soil hydraulic properties in a Cassava field as a function of soil dry bulk density. J. Jpn. Soc. Hyd. Water. Res. 18, (2), 156-166.

Nimmo, J.R. 1997. Modeling structural influences on soil water retention. Soil Sci. Soc. Am. J. 61, 712-719.

Novak, J.M., Busscher, W.J., Laird, D.L., Ahmedna, M., Watts, D.W., Niandou, M.A.S. 2009. Impact of biochar amendment on fertility of a southeastern coastal plain soil. Soil Sci. 174, 105-112.

Novak, M., Busscher, W.J., Watts, D.W., Laird D.A., Ahmedna M.A., Niandou M.A.S. 2010. Short-term $\mathrm{CO}_{2}$ mineralization after additions of biochar and switchgrass to a Typic Kandiudult. Geoderma. 154, 281-288.

Ouyang, L., Zhang, R. 2013. Effects of biochars derived from different feedstocks and pyrolysis temperatures on soil physical properties. J. Soil. Sediment. 13, 1561-1572. 
Pietikäinen, J., Kiikkilä, O., Fritze, H. 2000. Charcoal as a habitat for microbes and its effect on the microbial community of the underlying humus. Oikos. 89, 231-242.

Six, J., Bossuyt, H., Degryze, S., Denef, K. 2004. A history of research on the link between (micro) aggregates, soil biota, and soil organic matter dynamics. Soil Till. Res. 79, 7-31.

Tang, J., Mo, Y., Zhang, J., Zhang, R. 2011. Influence of biological aggregating agents associated with microbial population on soil aggregate stability. Appl. Soil Ecol. 47, 153-159.

Tisdall, J.M., Oades, J.M. 1982. Organic matter and water-stable aggregates in soils. J. Soil Sci. 62, 141-163.

Tuli, A., Hopmans, J.W., Rolston, D.E., Moldrup, P. 2005. Comparison of air and water permeability between disturbed and undisturbed soils. Soil Sci. Soc. Am. J. 69, 1361-1371. van Genuchten, M.Th. 1980. A closed form equation for predicting the hydraulic conductivity of unsaturated soils. Soil Sci. Soc. Am. J. 44, 892898.

Wick, A.F., Snehalata, H.V., Stahl, P.D. 2009. Use of Bayesian methods to model soil aggregation in undisturbed semiarid grasslands. Soil Sci. Soc. Am. J. 73, 1707-1714.

Zhang, R. 1997. Determination of soil sorptivity and hydraulic conductivity from the disc infiltrometer. Soil Sci. Soc. Am. J. 61, 1024-1030.

Zimmerman, A.R., Gao, B., Ahn, M.Y. 2011. Positive and negative carbon mineralization priming effects among a variety of biochar-amended soils. Soil Bio. Biochem. 43, 1169-1179. 